\title{
Factors Associated with Apgar Score among Newborns Delivered by Cesarean Sections at Gandhi Memorial Hospital, Addis Ababa
}

\author{
Mohammed Suleiman Obsa $\mathbb{D D}^{1}$ Getahun Molla Shanka, ${ }^{2}$ \\ Misrak Woldayohannes Menchamo, ${ }^{3}$ Robera Olana Fite $\mathbb{D D}^{4}{ }^{4}$ and Meron Abrar Awol ${ }^{3}$ \\ ${ }^{1}$ Department of Anesthesia, Wolaita Sodo University, Wolaita, Ethiopia \\ ${ }^{2}$ School of Medicine, Wolaita Sodo University, Wolaita, Ethiopia \\ ${ }^{3}$ Addis Ababa University School of Anesthesia, Addis Ababa, Ethiopia \\ ${ }^{4}$ Department of Nursing, Wolaita Sodo University, Wolaita, Ethiopia
}

Correspondence should be addressed to Mohammed Suleiman Obsa; msuleiman43@gmail.com

Received 24 September 2019; Revised 11 November 2019; Accepted 26 November 2019; Published 6 January 2020

Academic Editor: Marco Scioscia

Copyright (c) 2020 Mohammed Suleiman Obsa et al. This is an open access article distributed under the Creative Commons Attribution License, which permits unrestricted use, distribution, and reproduction in any medium, provided the original work is properly cited.

Background. Newborns can be assessed clinically using the Apgar score test to quickly and summarily assess the health of newborn physical condition immediately after delivery and to determine any immediate need for extra medical or emergency care. This study is aimed at assessing factors associated with Apgar score among newborns delivered by cesarean sections and factors associated with Apgar score. Method. Institutional-based cohort study design was conducted. All eligible study participants were included. Training was given for data collectors and supervisors. Regular supervision and follow-up was made. Data was entered into Epi Info version 7 computer software by investigators and was transported to SPSS version 20 computer program for analysis. Bivariate and multivariate analysis was used to identify factors associated with Apgar score. Result. A total 354 newborn babies were included into the study. Majority of baby had low Apgar score at one minute and high Apgar score at five minutes. About $30.2 \%$ of newborn baby had Apgar score below seven minutes. On the other hand, about $12.8 \%$ of all newborns had low Apgar score at five minutes. It had been found that those neonates who were born when skin incision to delivery time is greater than three minutes were about fourfolds more likely to have low Apgar score than those who were born when skin incision to delivery time is less than three minutes (AOR 3.645) (95\% CI (0.116-26.421)). Conclusion. Newborn babies have a low Apgar score at one minute as compared to five minutes. But low Apgar score at five minutes has long-term sequel. Therefore, it is very important to reduce factors associated with low Apgar score at both minutes.

\section{Introduction}

Newborns delivered by cesarian section (CS) can be assessed clinically using the Apgar score which was devised in 1952 by Dr. Virginia Apgar to evaluate the health of newborn and assess the effects of obstetric anesthesia on newborns at birth [1]. The test is simple and repeatable method to quickly and summarily assess the health of newborn physical condition immediately after delivery and to determine any immediate need for extra emergency care $[2,3]$.
Five factors are used to evaluate the baby's condition and each factor is scored on a scale of 0 to 2 , with 2 being the best score for each: the scoring system is an accepted tool for assessing the vitality of newborn infants. The score is based on measures of heart rate, respiratory effort, skin color, muscle tone, and reflex irritability [4].

Scores obtainable are between 0 and 10 , with 10 is the highest possible score. A total score of 7-10 is considered "normal," and a lower Apgar score indicates depressed vitality [5]. However, several possible causes of low Apgar 
TABLE 1

\begin{tabular}{lccc}
\hline Apgar score & 0 & 1 & 2 \\
\hline Heart rate & Absent & $>100$ & $>100$ \\
Respiratory effort & Absent & Irregular & Good \\
Reflex irritability & No response & Reflex irritability & Cough/sneeze \\
Appearance (color) & Blue or pale & Body pink with blue extremities & Completely pink \\
Muscle tone & Flaccid & Good tone & Spontaneous flexion \\
\hline
\end{tabular}

scores exist, such as perinatal asphyxia and congenital infections [6-9].

Apgar score is usually done to the baby twice: once at one minute after birth and again at 5 minutes after birth. Rarely, if there are concerns about the baby condition and the first two scores are low, less than 7 , the scoring is also performed at 10, 15, and 20 minutes after delivery $[10,11]$.

The 1 min Apgar score may signal the need for immediate resuscitation, and the Apgar score measured 5 min after birth is a predictor of neonatal mortality and several neurological outcomes [12-14].

\section{Method and Materials}

2.1. Study Setting. Cohort study design was conducted from January to March 2016 at Gandhi.

2.2. Source Population. This section discusses all newborn babies of mothers who gave birth by cesarian section at Gandhi Memorial Hospital, Addis Ababa.

2.3. Study Population. This section discusses selected newborn baby of mothers who gave birth by cesarian section from January to March at Gandhi Memorial Hospital, Addis Ababa.

2.4. Exclusion Criteria. This section discusses acute fetal distress, intrauterine fetal death, pregnancies with bleeding, and a mother who refused to take part in the study.

2.5. Data Collection Tools and Procedure. Data was collected using pretested structured questionnaires. Apgar score was done as per the protocol prescribed by the neonatal Advanced Life Support advocated by the American Pediatric Association. At delivery, for evaluation of neonate, Apgar scores were assigned at one and five minutes. It was based on the appearance (color), pulse rate, grimace (reflexes), muscle tone (activity), and respiratory effort of neonate each carrying a score from 0 to 2 (Table 1 ).

Apgar score scaling based on neonatal advanced life support is advocated by the American Pediatric Association (APA) [10].

2.6. Data Quality Assurance. The questionnaire was prepared in English first and translated to the local language, Amharic, and again back to translation to English was made to ensure that the consistency of the question. Pretest was done on $5 \%$ of the sample size at Zewditu Memorial Hospital. Data collectors and supervisors were trained on each items included in the study tools. Double entry was made on $10 \%$ of sample size.
2.7. Data Analyzing and Processing. The data was entered into Epi Info version 7 and transported to SPSS version 20 computer program for analysis. Bivariate and multivariate analysis was used to see the effect of independent variable over Apgar score. Variables which were significant on bivariate analysis at $p$ value less than 0.2 were taken to multivariate analysis. In multivariate analysis $p$ value of less than 0.05 was used as a cut of point for the presence of association. Strength of association was measured by $95 \%$ confidence interval and odd ratio.

2.8. Ethical Consideration. Ethical clearance and approval was obtained from ethical review committee, Anesthesia Department, Addis Ababa University. Permission to conduct was obtained from Gandhi Memorial Hospital. Informed verbal consent was secured from study participants. The obtained data was only used for study purpose. Confidentiality and anonymity were ensured.

\subsection{Operational Definition}

2.9.1. Cesarian Section. An intentional incision made on an intact uterus to delivery fetus.

2.9.2. Newborn. It refers specifically to the infant in the first minutes to hours after birth.

2.9.3. Neonate. It generally defined as an infant during the first 28 days of life. Infancy includes the neonatal period and extends through 12 months of age.

2.9.4. High Apgar Score. This section discusses Apgar scores of 7 or above.

2.9.5. Low Apgar Score. This section discusses Apgar scores below 7 .

\section{Result}

3.1. Sociodemographic and Personal Characteristics. A total 344 pregnant mothers gave birth to 354 newborns at Gandhi Memorial Hospital of which $37.20 \%$ were primigravida and $48.84 \%$ were multigravida. Pertaining to age of pregnant mother, the highest number of age group was found between 25 and 29 years and followed by the age group between 20 and 24 years of age. The mean age of respondents was $25.68 \pm$ SD (4.324) (minimum 20 and maximum 36). Only 24 of all pregnant mothers had hypertension induced by pregnancy and none of them had history of exposure to alcohol drinking and smoking. Almost all of pregnant mothers had single and most of them gave birth on an emmergency basis (see Table 2). 
TABLE 2: Sociodemographic and personal charateristics of pregnant mothers of newborns delivered by cesarean sections under general and spinal anesthesia from January to March 2016 at Gandhi Memorial Hospital.

\begin{tabular}{|c|c|c|c|}
\hline Variables & Category & Frequency & Percentage \\
\hline \multirow{4}{*}{ Age (in years) } & $20-24$ & 116 & 33.72 \\
\hline & $25-29$ & 132 & 38.37 \\
\hline & $30-34$ & 54 & 15.70 \\
\hline & 35-39 & 42 & 12.21 \\
\hline \multirow{4}{*}{ Pregnancy state } & Gravida I & 128 & 37.20 \\
\hline & Gravida II & 168 & 48.84 \\
\hline & Gravida III & 44 & 12.80 \\
\hline & Missing & 4 & 1.16 \\
\hline \multirow{2}{*}{ Types of gestation } & Single & 324 & 94.2 \\
\hline & Multiple gestation & 20 & 5.8 \\
\hline \multirow{3}{*}{ Maternal medical condition } & Hypertension & 24 & 6.97 \\
\hline & Gestational diabetes mellitus & 4 & 1.16 \\
\hline & Normal & 316 & 91.87 \\
\hline \multirow{2}{*}{ Type of C/S } & Emergency & 250 & 72.67 \\
\hline & Elective & 94 & 24.33 \\
\hline \multirow{2}{*}{ Type of anesthesia } & Spinal & 298 & 86.82 \\
\hline & General & 46 & 13.38 \\
\hline
\end{tabular}

TABLE 3: The fetal and newborn condition of pregnant mothers of newborns delivered by cesarean sections from January to March 2016 at Gandhi Memorial Hospital.

\begin{tabular}{|c|c|c|c|}
\hline Variables & Category & Frequency & Percentage \\
\hline \multirow{2}{*}{ Sex of the newborn baby } & Male & 210 & 58.14 \\
\hline & Female & 144 & 41.86 \\
\hline \multirow{3}{*}{ Birth weight } & 1.5 to $2.5 \mathrm{~kg}$ & 96 & 27.12 \\
\hline & 2.5 to $4 \mathrm{~kg}$ & 248 & 70.06 \\
\hline & Greater than $4 \mathrm{~kg}$ & 10 & 2.82 \\
\hline \multirow{3}{*}{ Gestational age in terms } & Preterm for GA & 18 & 5.08 \\
\hline & Term for GA & 310 & 87.57 \\
\hline & Postterm for GA & 26 & 7.35 \\
\hline \multirow{2}{*}{ Skin incision to delivery time } & $\leq 3$ minutes & 132 & 38.37 \\
\hline & $>3$ minutes & 212 & 61.63 \\
\hline
\end{tabular}

3.2. Fetal and Newborn Condition. Among 354 of newborns delivered by pregnant mothers, $58.14 \%$ were male. Majority of newborns had a normal birth weight and they were delivered at term. About $61.63 \%$ of all newborn were delivered when the skin incision to delivery time was greater than three minutes. Out of 46 newborns delivered under general anesthesia, $74 \%$ were delivered when induction to deliver time is more than six minutes (see Table 3 ).

3.3. Apgar Score Difference at One and Five Minutes. In this study, the effect of different factors over Apgar score of newborn babies was determined. About 30.2\% of newborn baby had Apgar score below seven while about $69.8 \%$ had high Apgar score at a minute. On the other hand, about $12.8 \%$ of all newborns had low Apgar score at five minutes while about 91.2\% had high Apgar score at five minutes. Generally, it was found that number of the newborn babies who had low Apgar score at one minute was reduced by more than a half as compared to Apgar score at five minutes (Table 4).

3.4. Determinants of Apgar Score at One Minute. Among all determinants of Apgar score at one minute age group, gestational age in terms, maternal heart rate, and type of cesarian section, maintenance agents, body mass index, and gestational type were not associated on bivariate analysis at $p$ value less than 0.2 , therefore excluded from multivariate analysis. It was observed from a data of multivariate analysis that skin incision to delivery time and type of 
TABle 4: Apgar score difference at one and five minutes among newborns delivered by cesarean sections from January to March 2016 at Gandhi Memorial Hospital.

\begin{tabular}{lccccc}
\hline \multirow{2}{*}{ Variable } & \multirow{2}{*}{ Category } & \multicolumn{2}{c}{ At one minute } & \multicolumn{2}{c}{ At five minutes } \\
& & Frequency & Percentage & Frequency & Percentage \\
\hline \multirow{2}{*}{ Apgar score } & Less than seven & 104 & 30.2 & 44 & 12.8 \\
& Seven to ten & 240 & 69.8 & 300 & 91.2 \\
\hline
\end{tabular}

TABle 5: Factors affecting Apgar score at one minute among newborns delivered by cesarean sections from January to March 2016 at Gandhi Memorial Hospital.

\begin{tabular}{|c|c|c|c|c|c|}
\hline \multirow{2}{*}{ Variable } & \multicolumn{2}{|c|}{ Category } & \multirow{2}{*}{ Sig. } & \multirow{2}{*}{$\begin{array}{c}\text { COR } \\
95 \% \text { C.I. }\end{array}$} & \multirow{2}{*}{$\begin{array}{c}\text { AOR } \\
\text { 95\% C.I. }\end{array}$} \\
\hline & High score & Low score & & & \\
\hline \multicolumn{6}{|c|}{ Type of anesthesia } \\
\hline General & 24 & 22 & .021 & $2.244(1.375-10.183)$ & $3.668(.276-10.145)$ \\
\hline Spinal & 216 & 82 & * & $*$ & $*$ \\
\hline \multicolumn{6}{|c|}{ Skin incision to delivery time } \\
\hline$<3$ minutes & 114 & 18 & $*$ & $*$ & * \\
\hline$>3$ minutes & 128 & 84 & .032 & $3.225(.035-6.218)$ & $3.645(0.116-26.421)$ \\
\hline \multicolumn{6}{|l|}{ Birth weight } \\
\hline $1.5-2.5 \mathrm{~kg}$ & 24 & 72 & .112 & $2.182(0.024-17.415)$ & $3.418(2.126-12.099)$ \\
\hline $2.5-4 \mathrm{~kg}$ & 216 & 32 & * & * & * \\
\hline \multicolumn{6}{|l|}{ Blood pressure } \\
\hline Normotension & 226 & 94 & $*$ & * & $*$ \\
\hline Hypertension & 14 & 10 & .456 & $.223(.004-46.839)$ & $1.229(.012-37.277)$ \\
\hline
\end{tabular}

anesthesia were strongly associated with a low Apgar score at $p$ value less than 0.05 . The odd of developing the low Apgar score when skin incision to delivery time was greater than three minutes was about three times as high as the odd of developing low Apgar score when skin incision to delivery time was less than three minutes at one minute (AOR 3.645) (95\% CI (0.116-26.421)) (Table 5).

3.5. Determinants of Apgar Score at Five Minutes. At five minutes, induction agents, anesthesia type, body mass index, type of $\mathrm{C} / \mathrm{S}$, and age group were not associated with bivariate analysis at $p$ value less than 0.2 , so that it was excluded from multivariate analysis. It was observed from a data of multivariate analysis that skin incision to delivery time, gestational age, and blood pressure were strongly associated with a low Apgar score at $p$ value less than 0.05. Being multiple gestations were about three times more likely to develop low Apgar score when compared to single gestation at five minutes (AOR 3.477) (95\% CI (.033-16.94)) (see Table 6).

\section{Discussion}

Majority of the pregnant mothers who gave birth by cesarean section were found between age group 25 and 29 of whom the mean age was $25.28 \pm \mathrm{SD}$ (4.267) (minimum 20 and maximum 38). The magnitude of low Apgar score was 30.2\% and $12.8 \%$ at one minute and five minutes, respectively, which is almost closest to review conducted in Uganda teaching hospital 28\% [15]. In contrast to this study, the magnitude of low Apgar score in Gondar University Hospital was high (37.5\%). The higher magnitude of low Apgar score in Gondar University Hospital could be attributed to preanesthetic condition as $92 \%$ of the cases were emergency $\mathrm{C} / \mathrm{S}$, fetal distress being the leading indication [16].

The result of this study also revealed that majority of newborn babies had better Apgar score both at one and five minutes. In addition, newborn who delivered under spinal anesthesia had a better Apgar score which is consistent with other similar studies $[17,18]$. This is in contrast with the finding of another study which reported as there is no statistically significant difference in Apgar scores between the two groups at 1 minute. However, more neonates of the general anesthesia group appeared depressed soon after birth, needing free flow of oxygen and bag and mask ventilation [19]. The low Apgar score at one minute may be due to the result of laryngeal spasm induced by aspiration of liquor or blood during intrauterine manipulation and pregnant mothers who received general anesthesia have relatively high level of circulating catecholamine causing a reduction in uteroplacental blood flow.

In line with other study [20], low birth weight (birth weight $<2.5 \mathrm{~kg}$ ) was found to be associated with low Apgar score at one minute and uterine incision to delivery time had association with Apgar score both at one and five minutes of postdelivery [21]. The low Apgar score in low birth weight infant may be due to very immaturity of organ and nervous systems that makes infant unable to adapt to the new environment.

Many workers have recommended that delivery is best completed 6-8 minutes after induction of general anesthesia 
TABLE 6: Factors affecting Apgar score at five minutes among newsborns delivered by cesarean sections under general and spinal anesthesia from January to March 2016 at Gandhi Memorial Hospital.

\begin{tabular}{|c|c|c|c|c|c|}
\hline \multirow{2}{*}{ Variable } & \multicolumn{2}{|c|}{ Category } & \multirow{2}{*}{ Sig. } & \multirow{2}{*}{$\begin{array}{c}\text { COR } \\
95 \% \text { C.I. }\end{array}$} & \multirow{2}{*}{$\begin{array}{c}\text { AOR } \\
95 \% \text { C.I. }\end{array}$} \\
\hline & High score & Low score & & & \\
\hline \multicolumn{6}{|l|}{ Gestational age } \\
\hline Term & 292 & 18 & * & * & * \\
\hline Postterm & 12 & 14 & 0.02 & $.037(.4612-5.483)$ & $3.824(.024-26.94)$ \\
\hline Preterm & 6 & 12 & 0.03 & $2.17(.272-10.332)$ & $5.477(.313-38.12)$ \\
\hline \multicolumn{6}{|c|}{ Uterine incision to delivery time } \\
\hline$<3$ minutes & 118 & 14 & * & * & * \\
\hline$>3$ minutes & 182 & 30 & .012 & $.126(.025-10.482)$ & $4.65(2.134-16.463)$ \\
\hline \multicolumn{6}{|l|}{ Birth weight } \\
\hline $1.5-2.5 \mathrm{~kg}$ & 80 & 16 & .215 & $1.122(.574-23.135)$ & $3.156(.026-18.352)$ \\
\hline $2.5-4 \mathrm{~kg}$ & 220 & 28 & * & * & * \\
\hline \multicolumn{6}{|l|}{ Blood pressure } \\
\hline Normotension & 290 & 32 & * & * & * \\
\hline Hypertension & 12 & 12 & .034 & $.187(.277-11.453)$ & $5.289(.147-28.35)$ \\
\hline \multicolumn{6}{|l|}{ Gestational type } \\
\hline Single & 288 & 36 & $*$ & $*$ & $*$ \\
\hline Multiple & 12 & 8 & .236 & $1.23(.012-4.45)$ & $1.477(0.024-12.84)$ \\
\hline
\end{tabular}

as inhalational agents could cause neonatal depression $[22,23]$. Another study reported that long induction to delivery time more than 8 minutes and uterine incision-todelivery time more than 180 seconds has been associated with fetal hypoxia and acidosis [23].

\section{Conclusion and Recommendation}

The result of the study indicated that newborn baby who delivered under general anesthesia has relatively low Apgar score when compared to those who delivered under spinal anesthesia.

Skin incisions to delivery time and type of anesthesia were strongly associated with a low Apgar score at one minute while kin incision to delivery time, gestational age, and blood pressure were found to be associated with low Apgar score at five minutes.

Therefore, it is very important to reduce factors eliciting low Apgar score.

\section{Abbreviations}

CS: Cesarian section

ICD: International Classification of Diseases.

\section{Data Availability}

The data used in this study was collected by data collectors and submitted to authors, who are willing to share the data upon request from peer researchers.

\section{Conflicts of Interest}

We declared that we had no competing interests.

\section{Authors' Contributions}

MS has contributed to the conception, design of the study, data acquisition, data entry, data analyses, result interpretation, manuscript development, and revision. GM, MW, RO, and MA have contributed to the conception, initial design of the study, data acquisition, data analyses, result interpretation, and manuscript development. All authors read and approved the final manuscript.

\section{Acknowledgments}

We would like to thank Addis Ababa University for the financial support. Addis Ababa University provided fund for data collectors.

\section{References}

[1] M. Berchicci, G. Tamburro, and S. Comani, "The intrahemispheric functional properties of the developing sensorimotor cortex are influenced by maturation," Frontiers in Human Neuroscience, vol. 9, p. 39, 2015.

[2] S. Iliodromiti, D. F. Mackay, G. C. S. Smith, J. P. Pell, and S. M. Nelson, "Apgar score and the risk of cause-specific infant mortality: a population- based cohort study," The Lancet, vol. 384, no. 9956, pp. 1749-1755, 2014.

[3] S. M. Nelson, S. Iliodromiti, D. F. Mackay, J. P. Pell, and G. C. S. Smith, "Apgar score and risk of cause-specific infant mortality - Authors' reply," Lancet, vol. 385, no. 9967, p. 506, 2015.

[4] S. Berglund, H. Pettersson, S. Cnattingius, and C. Grunewald, "How often is a low Apgar score the result of substandard care during labour?," BJOG: An International Journal of Obstetrics \& Gynaecology, vol. 117, no. 8, pp. 968-978, 2010. 
[5] J. S. Torday and H. C. Nielsen, "The molecular Apgar score: a key to unlocking evolutionary principles," Frontiers in Pediatrics, vol. 5, p. 45, 2017.

[6] S. Lai, C. Flatley, and S. Kumar, "Perinatal risk factors for low and moderate five-minute Apgar scores at term," European Journal of Obstetrics \& Gynecology and Reproductive Biology, vol. 210, pp. 251-256, 2017.

[7] L. Hogan, I. Ingemarsson, K. Thorngren-Jerneck, and A. Herbst, "How often is a low 5-min Apgar score in term newborns due to asphyxia?," European Journal of Obstetrics \& Gynecology and Reproductive Biology, vol. 130, no. 2, pp. 169-175, 2007.

[8] M. Landon, "National Institute of Child Health and Human Development Maternal-Fetal Medicine Units Network. Maternal and perinatal outcomes associated with a trial of labor after prior cesarean delivery," The New England Journal of Medicine, vol. 16, pp. 2581-2591, 2004.

[9] L. Wong and A. H. Maclennan, "Gathering the evidence: cord gases and placental histology for births with low Apgar scores," Australian and New Zealand Journal of Obstetrics and Gynaecology, vol. 51, no. 1, pp. 17-21, 2011.

[10] B. M. Casey, D. D. McIntire, and K. J. Leveno, "The continuing value of the Apgar score for the assessment of newborn infants," New England Journal of Medicine, vol. 344, no. 7, pp. 467-471, 2001.

[11] L.-A. Papile, The Apgar Score in the 21st Century, vol. 344, no. 7, 2001Mass Medical Soc, 2001.

[12] V. Ehrenstein, H. T. Sørensen, L. Pedersen, H. Larsen, V. Holsteen, and K. J. Rothman, "Apgar score and hospitalization for epilepsy in childhood: a registry-based cohort study," BMC Public Health, vol. 6, no. 1, 2006.

[13] C. Harden, P. Pennell, B. Koppel et al., "Practice parameter update: management issues for women with epilepsy-focus on pregnancy (an evidence-based review): vitamin $\mathrm{K}$, folic acid, blood levels, and breastfeeding report of the Quality Standards Subcommittee and Therapeutics and Technology Assessment Subcommittee of the American Academy of Neurology and American Epilepsy Society," Neurology, vol. 73, no. 2, pp. 142-149, 2009.

[14] Y. Sun, M. Vestergaard, C. B.??. Pedersen, J. Christensen, and J.??. Olsen, "Apgar scores and long-term risk of epilepsy," Epidemiology, vol. 17, no. 3, pp. 296-301, 2006.

[15] A. Yegin, Z. Ertuğ, M. Yilmaz, and M. Erman, "The effects of epidural anesthesia and general anesthesia on newborns at cesarean section," Turkish Journal of Medical Sciences, vol. 33, no. 5, pp. 311-314, 2003.

[16] Z. Abdissa, T. Awoke, T. Belayneh, and Y. Tefera, "Birth outcome after caesarean section among mothers who delivered by caesarean section under general and spinal anesthesia at Gondar University teaching hospital north-west Ethiopia," Journal of Anesthesia \& Clinical Research, vol. 04, no. 07, pp. 4-8, 2013.

[17] J. Hong, Y. Jee, H. Yoon, and S. Kim, “Comparison of general and epidural anesthesia in elective cesarean section for placenta previa totalis: maternal hemodynamics, blood loss and neonatal outcome," International Journal of Obstetric Anesthesia, vol. 12, no. 1, pp. 12-16, 2003.

[18] C. Loghis, E. Salamalekis, N. Panayotopoulos, N. Vitoratos, and P. A. Zourlas, "The effect of early second stage bradycardia on newborn status," European Journal of Obstetrics \& Gynecology and Reproductive Biology, vol. 72, no. 2, pp. 149-152, 1997.
[19] T. Martin, P. Bell, and O. Ogunbiyi, "Comparison of general anaesthesia and spinal anaesthesia for caesarean section in Antigua and Barbuda," West Indian Medical Journal, vol. 56, no. 4, pp. 330-333, 2007.

[20] N. Boo, "Neonatal resuscitation programme in Malaysia: an eight-year experience," Singapore Medical Journal, vol. 50, no. 2, pp. 152-159, 2009.

[21] J. A. Lemons, C. R. Bauer, W. Oh et al., "Very low birth weight outcomes of the National Institute of Child health and human development neonatal research network, January 1995 through December 1996," Pediatrics, vol. 107, no. 1, p. e1-e, 2001.

[22] M. Valtonen, J. Kanto, and P. Rosenberg, "Comparison of propofol and thiopentone for induction of anaesthesia for elective caesarean section," Anaesthesia, vol. 44, no. 9, pp. 758-762, 1989.

[23] J. Tumukunde, D. D. Lomangisi, O. Davidson, A. Kintu, E. Joseph, and A. Kwizera, "Effects of propofol versus thiopental on Apgar scores in newborns and peri-operative outcomes of women undergoing emergency cesarean section: a randomized clinical trial," BMC Anesthesiology, vol. 15, no. 1, 2015. 


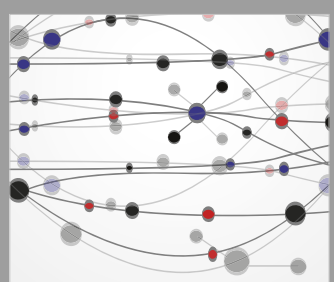

The Scientific World Journal
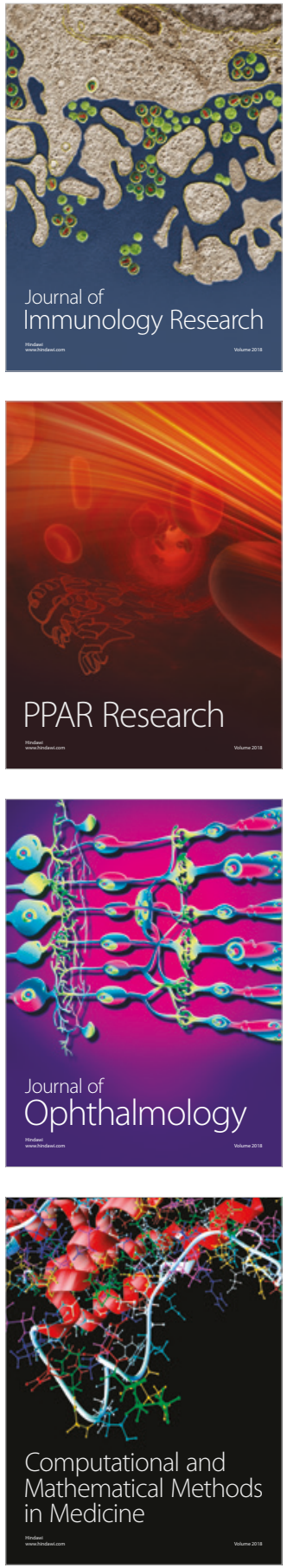

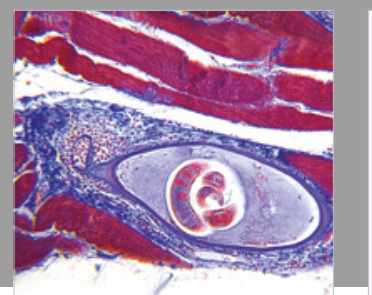

Gastroenterology Research and Practice

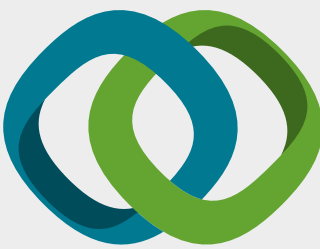

\section{Hindawi}

Submit your manuscripts at

www.hindawi.com
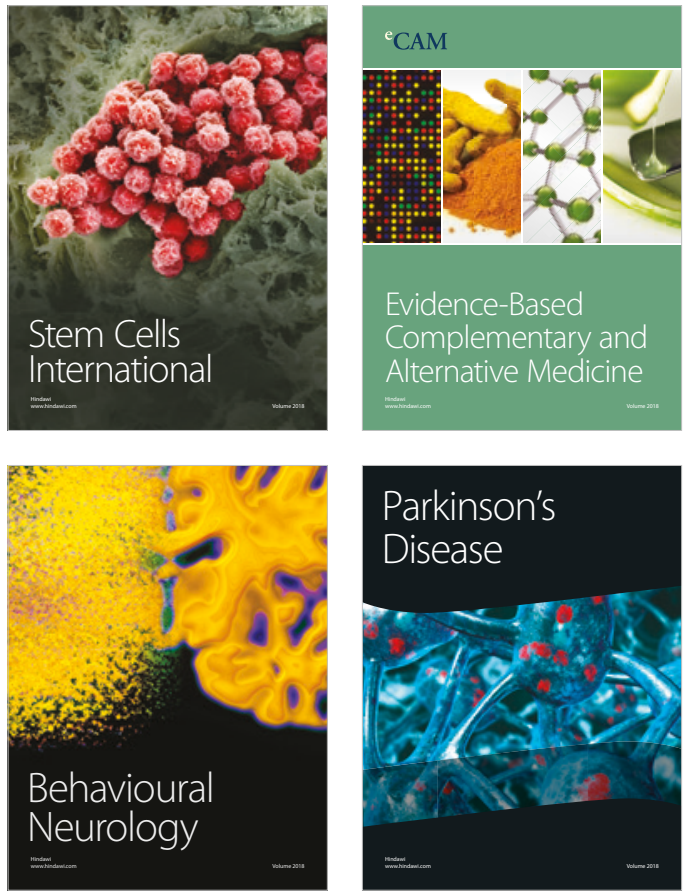

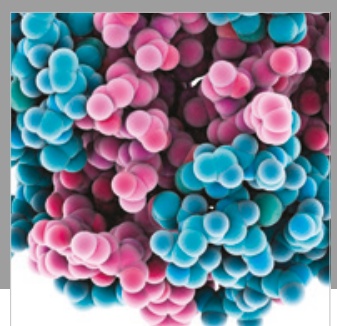

ournal of

Diabetes Research

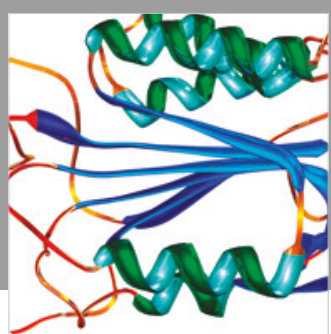

Disease Markers
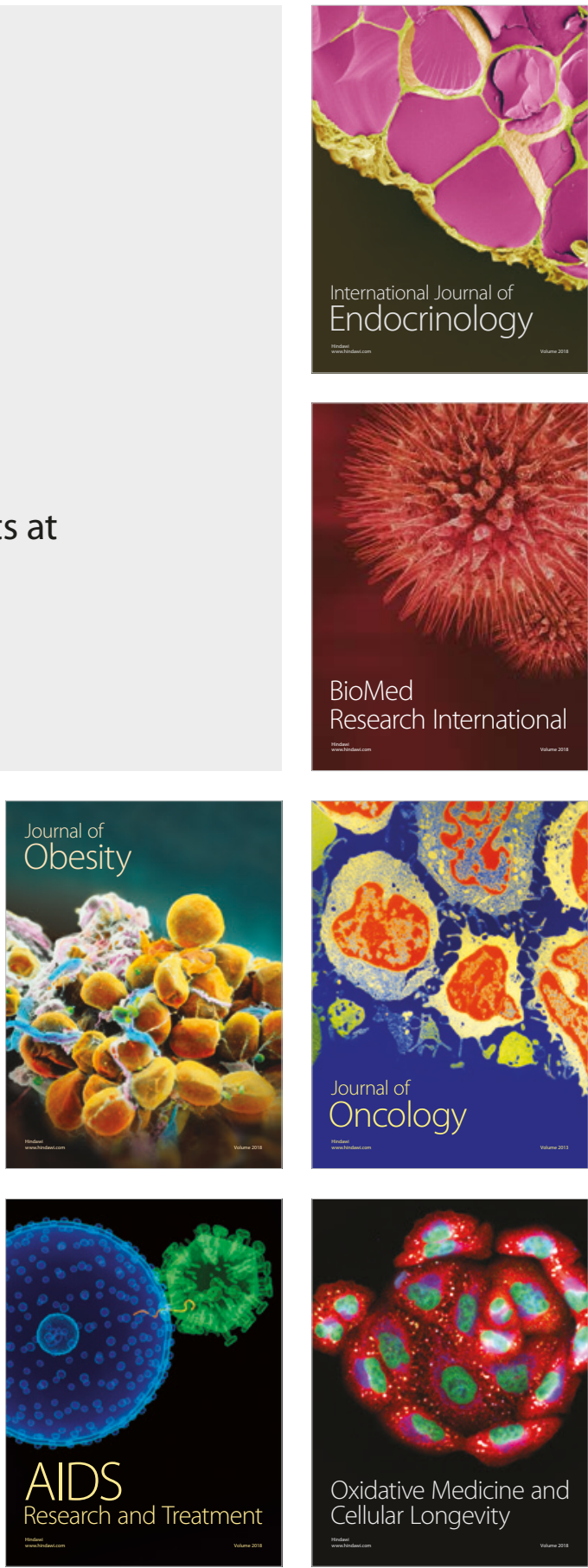